\title{
The discovery of historically extinct, but hitherto undescribed, species: an under-appreciated element in extinction-rate assessments
}

\author{
David L. Hawksworth • Robert H. Cowie
}

Published online: 4 August 2013

(c) Springer Science+Business Media Dordrecht 2013

\begin{abstract}
Estimates of the numbers of species that have become extinct during historic times may need to be reconsidered in view of issues that may not factor highly in academic consciousness. For example, there are (a) species that may have gone extinct since their collection, yet were never described, (b) species now extinct of which there are extant durable remains but that have not yet been collected or described, and (c) organisms that may have been dependent on species that are now extinct. The case of overlooked species that have become extinct in historic times is exemplified by the paper of Richling and Bouchet in this issue of Biodiversity and Conservation. This paper also emphasizes the need for detailed taxonomic study as a foundation for biodiversity conservation. However, as a matter of policy, the journal does not currently include articles with descriptions of novel taxa, but an exception is made here because of the importance of the phenomenon of extinction before description and to stress the role of taxonomy in biodiversity conservation, both being issues not always widely appreciated by conservation biologists and biodiversity scientists. Based on preserved shells, Richling and Bouchet report a radiation of helicinid land snails (nine new species and one previously described), from a group of Pacific islands, with eight of the nine new species and the single previously described species appearing to be extinct.
\end{abstract}

Keywords Associated species $\cdot$ Extinction rates $\cdot$ Herbaria $\cdot$ Museums $\cdot$ Snails

\author{
D. L. Hawksworth $(\bowtie)$ \\ Departamento de Biología Vegetal II, Facultad de Farmacia, Universidad Complutense de Madrid, \\ Plaza Ramón y Cajal, 28040 Madrid, Spain \\ e-mail: d.hawksworth@nhm.ac.uk \\ D. L. Hawksworth \\ Department of Life Sciences, The Natural History Museum, Cromwell Road, London SW7 5BD, UK \\ D. L. Hawksworth \\ Mycology Section, Royal Botanic Gardens, Kew, Surrey TW9 3DS, UK \\ R. H. Cowie \\ Pacific Biosciences Research Center, University of Hawaii, 3050 Maile Way, Gilmore 408, \\ Honolulu, HI 96822, USA
}




\section{Introduction}

The importance of biological reference collections of all kinds in understanding and documenting extant organisms is well-recognized. Such collections include those of botanical gardens, herbaria, microbial culture collections, museums, and research institutes (Heywood 1995; Rushton et al. 2001). Their importance ranges from the safeguarding of name-bearing types to ensure the accurate application of scientific names, to the use of collection data for biogeographical and historical studies and the preservation of voucher material necessary to verify particular records. Specimens of species that have not been named and described abound in museums, and Costello et al. (2013) suggested that there could be as many as 0.5 million unnamed species already in collections. In the case of flowering plants, Bebber et al. (2010) estimated that around half of the 70,000 species still to be described had already been collected and were stored in herbaria while, for the fungi, Hawksworth and Rossman (1997) suggested that there could be more than 20,000 undescribed species present in collections. The same situation undoubtedly applies to animal groups and protists, as well as microbes maintained in collections of living cultures. The proportion of such undescribed extinct species in collections is unknown, but cases have been demonstrated. Richling and Bouchet (2013), in this issue, cite some examples drawn from different groups of organisms.

In addition to species already in collections, historically extinct, but undescribed, species can be discovered from durable remains such as the hard parts of animals and plants. This is commonplace in palaeontology, but rarely considered for historical extinctions except in the notable case of bird remains on Pacific Islands (Pimm et al. 2006). The case involving snail shells (Richling and Bouchet 2013), shows just how important this can be in some other groups of less well-studied organisms.

\section{Implications of extinction before description}

The occurrence of species that have become extinct prior to description or collection has profound implications for estimates of rates of species extinction. While some of the already-collected but undescribed species, and ones described from newly discovered remains, will still be present living in the wild, others will not.

When attempts are made to obtain figures of recorded extinctions so that global estimates of species loss can be made, the issues of undescribed species already in collections and those represented by undiscovered durable remains are generally ignored. It would seem, therefore, that estimates of extinction rates in historical times, which are based on extinctions of known species (e.g. Dirzo and Raven 2003), will necessarily be underestimates.

Biodiversity and Conservation is not a taxonomic journal, and the current policy is not to accept submissions that include new species descriptions. However, following discussion between the Publishers and ourselves (as Editor-in-Chief and Corresponding Editor, respectively), an exception is made here for the paper of Richling and Bouchet (2013). This unusual step has been taken as that paper serves to emphasise, to all conservation biologists and biodiversity scientists, that recorded historical species extinctions will always underestimate the true situation in diverse groups of organisms. It also implicitly emphasizes the key role of and need for detailed taxonomic study (Sluys 2013), especially of lesser known groups (Ponder and Lunney 1999), as the foundation for comprehensive biodiversity conservation. If there are indeed sufficient numbers of taxonomists worldwide to cope with 
the task of describing all eukaryote species on Earth as Costello et al. (2013) argue, it is evident that efforts need to be re-directed towards the least known groups, notably fungi, invertebrates and protists.

Based on both newly collected and historic museum material, Richling and Bouchet (2013) discovered a radiation of hitherto undescribed species of endemic helicinid land snails, in the Gambier Islands of French Polynesia, that had become extinct probably in the latter part of the nineteenth century. These were represented in the top soil by empty shells. This single study increases the global number of recorded mollusc extinctions by almost $2 \%$. A similar paper was recently published on a radiation of extinct but undescribed endodontid land snails from Rurutu, also in French Polynesia, but in the taxonomic literature and so unlikely to be noticed by the biodiversity conservation community (Sartori et al. 2013).

As pointed out by Stork (2010), with reference to birds in Pacific Islands in general, it is difficult to argue that this phenomenon, extinction before description, can be extrapolated directly to continental land masses. However, evolutionary radiation in island systems often leads to the presence of numerous narrowly endemic species. These narrow island endemics are particularly susceptible to extinction through the impacts of invasive species and as a result of other anthropogenic changes. Snails are especially vulnerable and oceanic island snails, particularly in the Pacific, constitute by far the largest group of extinct land snails (Régnier et al. 2009).

It must also be borne in mind that species do not exist in isolation. In the case of plants, Raven (1976) estimated that the extinction of a single plant species is "on the average, accompanied by a 10-30 fold loss amongst other organisms". An independent analysis of the numbers of bacteria, insects, fungi, nematodes and viruses known only as associates of particular well-studied flowering plant species suggested 20, and a working figure of 15 was commended (Hawksworth 1998). How this figure relates to organisms other than flowering plants, including both vertebrate and invertebrate animals, is currently unknown. In some cases, however, dependent organisms will have been described in the absence of any information that they were dependents.

\section{Conclusion}

Estimates of historical species extinction rates are likely to be underestimates if they do not endeavour to allow for: (1) species represented only in collections and not yet formally described; (2) species preserved as durable remains but not hitherto collected and described; and (3) dependent organisms associated with those undescribed species that may or may not have previously been recognized. Taxonomic study is thus the key to developing accurate estimates of extinction rates, especially of many of the lesser known groups that constitute the vast majority of biodiversity, as well as being crucial as the underpinning of efforts to conserve the remaining extant species in such groups.

Acknowledgments This note was prepared while DLH was in receipt of funding from the Spanish Ministerio de Ciencia e Innovación project CGL2011-25003.

\section{References}

Bebber DP, Carine MA, Wood JRI, Wortley AH, Harris DJ, Prance GT, Davidse G, Paige J, Pennington TD, Robson NBK, Scotland RW (2010) Herbaria are a major frontier for species discovery. PNAS 107:22169-22171 
Costello MJ, May RM, Stork NE (2013) Can we name Earth's species before they go extinct? Science 339:413-416

Dirzo R, Raven PH (2003) Global state of biodiversity and loss. Ann Rev Environ Resour 28:137-167

Hawksworth DL (1998) The consequences of plant extinctions for their dependent biotas: an overlooked aspect of conservation science. In: Peng C-I, Lowry PP (eds) Rare, threatened, and endangered floras of Asia and the Pacific rim. Academia Sinica, Taipei, pp 1-15

Hawksworth DL, Rossman AY (1997) Where are all the undescribed fungi? Phytopathology 87:888-891

Heywood VH (ed) (1995) Global biodiversity assessment. Cambridge University Press, Cambridge

Pimm S, Raven P, Peterson A, Şekercioğlu ÇH, Ehrlich PR (2006) Human impacts on the rates of recent, present, and future bird extinctions. PNAS 103:10941-10946

Ponder WF, Lunney D (1999) The other 99\%: the conservation and biodiversity of invertebrates. The Royal Zoological Society of New South Wales, Mosman

Raven PH (1976) Ethics and attitudes. In: Simmons JB, Beyer RI, Brandham PE, Lucas GL, Parry UTH (eds) Conservation of threatened plant species. Plenum, New York, pp 155-179

Régnier C, Fontaine B, Bouchet P (2009) Not knowing, not recording, not listing: numerous unnoticed mollusk extinctions. Conserv Biol 23:1214-1221

Richling I, Bouchet P (2013) Extinct before scientific recognition: a remarkable radiation of helicinid snails (Helicinidae) on the Gambier Islands French Polynesia. Biodiv Conserv 22. doi:10.1007/s10531-0130496-2

Rushton BS, Hackney P, Tyrie CR (eds) (2001) Biological collections and biodiversity. Westbury Academic and Scientific Publishing, Otley

Sartori AF, Gargominy O, Fontaine B (2013) Anthropogenic extinction of Pacific land snails: a case study of Rurutu, French Polynesia, with description of eight new species of endodontids (Pulmonata). Zootaxa 3640:343-372

Sluys R (2013) The unappreciated, fundamentally analytical nature of taxonomy and the implications for the inventory of biodiversity. Biodiv Conserv 22:1095-1105

Stork NE (2010) Re-assessing current extinction rates. Biodiv Conserv 19:357-371 